\title{
MMRR \\ 2014: Volume 4, Number 2
}

A publication of the Centers for Medicare \& Medicaid Services, Office of Information Products \& Data Analytics

\section{Use of Hospitalists by Medicare Beneficiaries: A National Picture}

\author{
W. Pete Welch, ${ }^{1}$ Sally C. Stearns,${ }^{2}$ Alison E. Cuellar, ${ }^{3}$ and Andrew B. Bindman ${ }^{1,4}$ \\ ${ }^{1}$ Department of Health and Human Services-Assistant Secretary of Planning and Evaluation \\ ${ }^{2}$ University of North Carolina at Chapel Hill-Health Policy and Management \\ ${ }^{3}$ George Mason University-Health Administration and Policy \\ ${ }^{4}$ University of California San Francisco-PRL-Institute for Health Policy Studies
}

Objective: To describe the characteristics of hospitalists serving Medicare beneficiaries.

Data Sources: Medicare claims from 2009 and 2011 merged with the Provider Enrollment, Chain, and Ownership System file for physician characteristics.

Study Design: Our construction of the Medicare Data on Physician Practice and Specialty (MD-PPAS) enabled identification of hospitalists based on the attending physician for Medicare admissions (medical and surgical) in 2009 and 2011.

Principal Findings: In 2011, hospitalists constituted $13.3 \%$ of physicians who designated their specialty as primary care and $4.4 \%$ of all physicians serving Medicare beneficiaries. Compared to other physicians, hospitalists were more likely to be female, under forty, and in large practices. More than a quarter of Medicare admissions had a hospitalist as the attending physician, though the rate was substantially higher for medical than surgical admissions (31.8\% versus 11.3\%). Between 2009 and 2011, the percentage of medical admissions with a hospitalist as the attending physician increased by roughly a quarter (from $25.7 \%$ to $31.8 \%$ ).

Conclusions: This analysis provides a more current and complete estimate of the use of hospitalists by the Medicare population than is available from prior studies. The ability to identify hospitalists from claims data will facilitate research on the impact of hospitalist use on quality and cost.

Keywords: hospitals, Medicare, physicians, hospitalists, specialty

ISSN: 2159-0354

doi: http://dx.doi.org/10.5600/mmrr.004.02.b01 


\section{Medicare \& Medicaid Research Review} 2014: Volume 4, Number 2

\section{Mission Statement}

Medicare \& Medicaid Research Review is a peerreviewed, online journal reporting data and research that informs current and future directions of the Medicare, Medicaid, and Children's Health Insurance programs. The journal seeks to examine and evaluate health care coverage, quality and access to care for beneficiaries, and payment for health services.

\section{http://www.cms.gov/MMRR/}

\section{U.S. Department of Health \& Human Services Kathleen Sebelius Secretary}

\section{Centers for Medicare \& Medicaid Services Marilyn Tavenner Administrator}

Editor-in-Chief

David M. Bott, Ph.D.

The complete list of Editorial Staff and Editorial Board members may be found on the MMRR Web site (click link): $\underline{\text { MMRR Editorial Staff Page }}$

Contact: $\underline{\text { mmrr-editors@cms.hhs.gov }}$

Published by the Centers for Medicare \& Medicaid Services.

All material in the Medicare \& Medicaid Research

Review is in the public domain and may be duplicated without permission. Citation to source is requested.

\section{Background}

The last two decades have been characterized by changing roles and relationships between hospitals and physicians (Berenson, Ginsburg, \& May, 2007). One trend of particular importance has been the increasing use of hospitalists, physicians whose primary professional focus is to oversee and coordinate inpatient care (Wachter \& Goldman, 1996). The description of a physician role as a hospitalist emerged in 1996, and the number of physicians functioning as hospitalists is thought to have increased dramatically since then. An analysis of Medicare claims found that the percentage of general internists, the most common specialty pathway for hospitalists, who functioned as hospitalists increased from $5.9 \%$ in 1995 to $19.0 \%$ in 2006 (Kuo, Sharma, Freeman, \& Goodwin, 2009). Factors that may have contributed to the growth in the use of hospitalists include cost pressures, time pressures, decreasing inpatient volume for primary care physicians, patient flow in hospitals combined with the increasing complexity of inpatient medicine, rising malpractice costs, and the growing recognition of problems with patient safety (Pham, Devers, Kuo, \& Berenson, 2005).

Tracking the actual number of hospitalists has been challenging because hospitalists do not have specialty-specific training oversight or a certifying board. The Society of Hospital Medicine, the largest professional organization dedicated to this group of providers, reports on their Web site that the number of hospitalists exceeded 30,000 in 2010 (Society of Hospital Medicine, 2011). A national survey conducted by the Association of American Medical Colleges from the same year estimated that there were as many as 22,900 hospitalists trained in primary care specialties (internal medicine, family practice, pediatrics, and general 
practice) and as many as 29,700 if one also includes physicians trained in subspecialties of medicine, pediatrics, and obstetrics-gynecology (Association of American Medical Colleges, 2012).

This Data Brief updates the estimates of hospitalist physicians serving Medicare beneficiaries through 2011 and examines changes in the role these physicians play as the attending for medical and surgical admissions between 2009 and 2011. We describe hospitalists in 2011 in terms of their gender and age as well as the size and composition of their group practices. In performing this analysis, we demonstrate a method that can be used to track the number and growth of hospitalists participating in the Medicare program through administrative data.

\section{Methods}

The analysis uses a national database of physicians serving Medicare beneficiaries to identify and characterize hospitalists. Data on physicians' specialty were merged with Medicare inpatient claims at acute-care hospitals to identify hospitalists and to determine whether a hospitalist or non-hospitalist served as the attending physician for each medical or surgical admission.

We first identified physicians serving Medicare beneficiaries using the Medicare Data on Physician Practice and Specialty (MD-PPAS). The development of this database is described elsewhere (Welch, Cuellar, Stearns, \& Bindman, 2013). Briefly, the MD-PPAS was created using two Medicare administrative databases to characterize physicians and assign them to practices: (1) the Medicare Provider Enrollment, Chain, and Ownership System (PECOS) and (2) the 100\% physician/supplier file of fee-for-service Part B claims. Records from these two files were linked at the individual physician level using the national provider identifier (NPI). All data were available under agreement (No. 21990) with the Centers for Medicare \& Medicaid Services.

The PECOS maintains information on a physician's self-reported age, sex, and specialty. The MD-PPAS groups physicians (allopathic and osteopathic) into one of six broad specialties based on their primary specialty as most recently reported in PECOS: primary care (general practice, family medicine, internal medicine, pediatrics, and geriatrics), medical specialty, surgical specialty, psychiatry, obstetrics/gynecology, and hospital-based specialty (radiology, anesthesiology, emergency medicine, pathology).

We identified hospitalists as physicians trained in the primary care (or what are sometimes referred to as generalist) fields of family medicine, general practice, general internal medicine, general pediatrics, or geriatrics who billed at least 90 percent of their total charges in a year for Medicare in inpatient settings. We calculated the percentage of Medicare admissions in which a hospitalist was the attending physician. Medicare inpatient claims define the attending physician as "the physician who has overall responsibility for the beneficiary's care and treatment" (Research Data Assistance Center, 2013). Admissions were subcategorized as medical or surgical based on DRG code in the Medicare claims (Centers for Medicare \& Medicaid Services, 2013).

The Tax Identification Number (TIN) on the linked claims was used to identify physician group practices. Although physicians serving Medicare Advantage (MA) enrollees do not routinely submit claims to Medicare for MA enrollees, many physicians who are part of managed care organizations submit at least one fee-for-service claim to Medicare (e.g., for non-enrollees who seek emergency care). The number of physicians assigned to a TIN represented the group size. To characterize the distribution of non-hospitalists who are in group practices with hospitalists, we placed all practices with hospitalists into one of three categories based on their percentage 
of hospitalists: (1) practices in which hospitalists constituted more than $70 \%$ of the physicians; (2) practices in which hospitalists accounted for $30-70 \%$ of physicians; and (3) practices in which hospitalists constituted less than $30 \%$ of physicians.

\section{Results}

\section{Hospitalists and their Practices}

Based on a combination of physician specialty and Medicare billing patterns, we identified 25,787 hospitalists serving Medicare patients in 2011 (Exhibit 1). Hospitalists constituted 13.3\% of physicians who designated their specialty as primary care and $4.4 \%$ of all physicians billing Medicare (Exhibit 1). Female physicians were more likely to be hospitalists than males $(6.2 \%$ versus $3.8 \%$ of total physicians, $\mathrm{p}<0.01$ ). Younger physicians were also more likely to be hospitalists $(\mathrm{p}<0.01)$. Physicians in solo or small group practices were much less likely to be hospitalists than physicians in larger practices $(\mathrm{p}<0.01)$.

The percentage of physicians who might be considered hospitalists (i.e., those for whom inpatient charges constitute $90 \%$ of total charges) varies by specialty (Exhibit 2). Among physicians who self-designated to be in primary care, $22 \%$ of general internists have at least $90 \%$ of their charges for inpatient services, but physicians in family practice and general practice have only 4 or $3 \%$, respectively. Among pediatricians, $19 \%$ have at least $90 \%$ of their charges as inpatient, but this estimate may be inflated,

Exhibit 1. Hospitalists by Age, Sex, and Practice Size, 2011

\begin{tabular}{|c|c|c|c|c|c|}
\hline \multirow[b]{4}{*}{ Characteristic } & \multicolumn{3}{|c|}{ Physicians Serving Medicare Beneficiaries } & \multirow{2}{*}{\multicolumn{2}{|c|}{ Hospitalists as \% o }} \\
\hline & \multirow[b]{3}{*}{ Hospitalists } & \multirow{3}{*}{$\begin{array}{c}\text { Primary Care } \\
\text { (self-designated) }\end{array}$} & \multirow[b]{3}{*}{ Total Physicians } & & \\
\hline & & & & \multicolumn{2}{|l|}{ Primary } \\
\hline & & & & Care & Total \\
\hline Total & 25,787 & 194,566 & 580,638 & 13.3 & 4.4 \\
\hline \multicolumn{6}{|l|}{ Gender } \\
\hline Male & 16,059 & 127,601 & 423,060 & 12.6 & 3.8 \\
\hline Female & 9,728 & 66,965 & 157,578 & 14.5 & 6.2 \\
\hline \multicolumn{6}{|l|}{ Age } \\
\hline $26-39$ & 13,116 & 46,902 & 125,135 & 28.0 & 10.5 \\
\hline $40-59$ & 11,234 & 109,909 & 331,298 & 10.2 & 3.4 \\
\hline $60-79$ & 1,396 & 36,201 & 120,431 & 3.9 & 1.2 \\
\hline $80-89$ & 36 & 1,463 & 3,581 & 2.5 & 1.0 \\
\hline missing & 5 & 91 & 193 & 5.5 & 2.6 \\
\hline \multicolumn{6}{|l|}{ Practice Size } \\
\hline solo & 1,141 & 41,264 & 107,856 & 2.8 & 1.1 \\
\hline 2-10 MDs & 3,213 & 41,295 & 141,286 & 7.8 & 2.3 \\
\hline $11-50 \mathrm{MDs}$ & 6,871 & 36,240 & 124,573 & 19.0 & 5.5 \\
\hline 51-100 MDs & 3,991 & 19,530 & 48,867 & 20.4 & 8.2 \\
\hline$>100 \mathrm{MDs}$ & 10,571 & 56,237 & 158,056 & 18.8 & 6.7 \\
\hline
\end{tabular}


Exhibit 2. Physicians with More Than $90 \%$ of their Charges from Inpatient Settings, by Selected Specialties, 2011

\begin{tabular}{|c|c|c|c|}
\hline \multirow[b]{2}{*}{ Primary specialty } & \multirow[b]{2}{*}{ \# of MDs } & \multicolumn{2}{|c|}{$\begin{array}{c}\text { MDs with }>90 \% \\
\text { of charges inpatient }\end{array}$} \\
\hline & & $\#$ & $\%$ \\
\hline Primary Care & 194,566 & 25,787 & 13 \\
\hline Internal medicine & 95,170 & 20,849 & 22 \\
\hline Family practice & 81,604 & 2,874 & 4 \\
\hline Pediatric medicine & 8,006 & 1,521 & 19 \\
\hline General practice & 6,527 & 210 & 3 \\
\hline Other & 3,259 & 333 & 10 \\
\hline Medical Specialties & 103,801 & 5,744 & 6 \\
\hline Cardiology & 22,330 & 564 & 3 \\
\hline Neurology & 12,947 & 805 & 6 \\
\hline Gastroenterology & 12,183 & 229 & 2 \\
\hline Dermatology & 10,492 & 12 & 0 \\
\hline Pulmonary disease & 8,712 & 1,180 & 14 \\
\hline Hematology/oncology & 7,561 & 238 & 3 \\
\hline Nephrology & 7,387 & 381 & 5 \\
\hline Infectious disease & 4,924 & 1,962 & 40 \\
\hline Other & 17,265 & 373 & 2 \\
\hline OB-GYN & 32,153 & 637 & 2 \\
\hline
\end{tabular}

NOTE: Primary care includes hospitalists.

SOURCE: Authors' analysis of Medicare administrative data.

because the relatively small number of children enrolled in Medicare are eligible by virtue of being disabled; hence, they have a very high admission rate.

Among medical specialties, $6 \%$ of physicians have at least $90 \%$ of their charges in inpatient settings. Among two groups of medical specialists, pulmonologists and infectious disease specialists, the rate is substantially higher $(14 \%$ and $40 \%$ respectively).

In 2011, slightly less than a quarter of hospitalists $(23 \%)$ were in practices in which they were the numerically dominant specialty $(>70 \%$ of physicians), about the same proportion (23\%) were in practices in which they were a major component (30-70\% of physicians), and $54 \%$ of hospitalists were in practices in which they accounted for less than $30 \%$ of the physicians in the practice.
Hospitalists were more likely to practice with primary care physicians than surgeons. Whereas the ratio of primary care physicians to surgeons was 1.7-to- 1 for physicians as a whole, it was 32 -to- 1 in hospitalist-dominant practices, 6 -to- 1 in practices in which hospitalists were a major component, 2.3-to-1 in the other practices with hospitalists, and 1.5-to-1 in practices with no hospitalists.

\section{Growth in Hospitalists as a Percentage of Physicians and of Attending Physicians}

Hospitalists as a proportion of all Medicare physicians grew from $3.9 \%$ in 2009 to $4.4 \%$ in 2011 (Exhibit 3). Whereas the number of hospitalists increased 22.9\% in the two-year period, the number of physicians increased only $7.1 \%$, resulting in hospitalists as a proportion of physicians increasing by $14.7 \%$. 
Exhibit 3. Hospitalists as a Percentage of Physicians and of Attending Physicians, 2009 to 2011

\begin{tabular}{|c|c|c|c|c|}
\hline \multirow[b]{2}{*}{ Metric } & \multirow[b]{2}{*}{2009} & \multirow[b]{2}{*}{2011} & \multicolumn{2}{|c|}{ Change } \\
\hline & & & Absolute & $\%$ \\
\hline \multicolumn{5}{|l|}{ Physicians } \\
\hline Hospitalists & 20,987 & 25,787 & 4,800 & 22.9 \\
\hline All & 542,006 & 580,638 & 38,632 & 7.1 \\
\hline Hospitalists \% & $3.9 \%$ & $4.4 \%$ & $0.6 \%$ & 14.7 \\
\hline \multicolumn{5}{|l|}{$\underline{\text { Admissions }}$} \\
\hline \multicolumn{5}{|l|}{ Total } \\
\hline \# of admissions (000s) & 12,647 & 12,171 & -476 & -3.8 \\
\hline$\%$ with a hospitalist as the attending & $20.7 \%$ & $26.1 \%$ & $5.4 \%$ & 26.0 \\
\hline \multicolumn{5}{|l|}{ Medical } \\
\hline \# of admissions (000s) & 8,956 & 8,773 & -183 & -2.0 \\
\hline$\%$ with a hospitalist as the attending & $25.7 \%$ & $31.8 \%$ & $6.1 \%$ & 23.9 \\
\hline \multicolumn{5}{|l|}{ Surgical } \\
\hline \# of admissions (000s) & 3,691 & 3,397 & -294 & -8.0 \\
\hline$\%$ with a hospitalist as the attending & $8.6 \%$ & $11.3 \%$ & $2.7 \%$ & 31.3 \\
\hline
\end{tabular}

Among the 12.2 million Medicare admissions in $2011,26.1 \%$ had a hospitalist as the attending physician on the claim. This percentage was substantially higher for medical than surgical admissions (31.8\% versus 11.3\%). Between 2009 and 2011, the percentage of medical admissions with a hospitalist as the attending physician increased by almost a quarter from $25.7 \%$ to $31.8 \%$.

\section{Discussion}

This analysis provides a more current and complete estimate of the use of hospitalists by the Medicare population than is available from prior studies. The analysis reveals not only that hospitalists were the attending physician for almost a third of medical admissions in 2011 , but that the rate of use of hospitalists as attending increased more than a quarter over a two-year period. If this rate of increase continues, hospitalists trained in primary care specialties will serve as the attending physician for half of Medicare's medical admissions by 2017 .

The growth in hospitalists has implications not only for hospital-based care, but also for the supply of physicians available to meet Medicare beneficiaries' needs for primary care services. The number and percentage of graduating U.S. medical students entering residency training in primary care specialties has declined over time (American College of Physicians, 2006). This trend has raised questions about whether we are facing a shortage in the number of primary care physicians, particularly as demand for care increases in association with the aging of the population and the expansion of coverage related to the Affordable Care Act (Health Resources and Services Administration, 2013). If, as our data suggest, a growing percentage of young physicians training in primary care specialties subsequently pursue careers as hospitalists rather than primary care physicians, the shortage of physicians in primary care could become more severe than anticipated. 
Our estimate of the number and growth of hospitalists is based on claims from physicians trained in primary care specialties as well as on their role as attending physicians for inpatient stays. We do not capture cases in which these physicians may serve as consultants for hospital stays for which they are not the attending physicians. Thus, our estimate of the involvement of hospitalists in the care of surgical patients based on their being the attending physician is lower than that reported in studies that also counted these physicians' roles as consultants (Kuo et al., 2009).

Our data suggest that some physicians trained as medical specialists serve as hospitalists. While we believe that some specialists serve as hospitalists, we also suspect that estimating the number of hospitalists using the $90 \%$ inpatient charges criterion may be less specific for medical specialists than for those trained in primary care, whose main alternatives for inpatient charges are office or outpatient based charges. Physicians in some medical specialties may achieve the $90 \%$ rate of inpatient billing not only through their role as the attending physician responsible for patients on medical or surgical wards, but also through consultative roles.. In these cases, the inpatient charges observed in the claims data would not exclusively reflect these physicians' roles as hospitalists caring for patients on a medical or surgical ward. A large consultative role in combination with a small role as an attending physician on a medical or surgical unit during the year might explain the high number of hospitalists we estimate among physicians trained in infectious disease. In addition, by serving as the attending physician in specialized units, some specialists (such as pulmonary specialists in an intensive care unit) may also come to an incorrect conclusion that they are hospitalists using the $90 \%$ of Medicare charges criterion.

Another limitation is that we are only able to observe Medicare charges, so the approach underrepresents pediatricians, obstetricians, and other physicians less likely to participate in the care of the elderly population. It is possible that our estimates on the number of hospitalists would be altered by having claims from other payers, but repeated observations in Medicare claims over time still provide insights into the growth of hospitalists over time.

Future research should attempt to better understand the reasons for the growth in the use of hospitalists as the attending physician for hospitalized Medicare beneficiaries. Research on the use of hospitalists for the care of hospitalized patients has suggested that they may contribute to the reduction in the average length of a hospital stay (Meltzer et al., 2002). However, there is a paucity of information on whether hospitalists contribute to lower overall cost of care or lead to improvements in the quality of hospitalbased care and, most particularly, patients' outcomes. The ability to identify hospitalists from claims data as developed within this analysis can facilitate research on these important outcomes of care that could then be factored into future workforce planning.

\section{Disclaimer}

The authors have no conflicts of interest related to this analysis. The content is solely the responsibility of the authors and does not necessarily reflect the views of the Department of Health and Human Services. The research was funded internally by HHS/ASPE. The data were available through a data use agreement (No. 21990) between the Office of the Assistant Secretary for Planning and Evaluation of the Department of Health and Human Services and the Centers for Medicare and Medicaid Services.

\section{Correspondence}

W. Pete Welch, Ph.D., Department of Health and Human Services-Assistant Secretary for Planning and Evaluation (ASPE), 200 Independence Ave., SW Washington, DC 20201, Pete.Welch@hhs.gov, Tel. 202-260-6213

\section{Acknowledgment}

The authors appreciate programming support from Acumen LLC. 


\section{References}

American College of Physicians (2006, January 30) Theimpending collapse of primary care medicine and its implications for the state of the nation's health care. Washington, D.C. Retrieved from http://www.acponline.org/advocacy/advocacy_ in_action/state_of_the_nations_healthcare/ assets/statehc06_1.pdf

Association of American Medical Colleges (2012).

Estimating the Number and Characteristics of Hospitalist Physicians in the United States and Their Possible WorkforceImplications. Retrieved from https://www.aamc.org/download/300620/ data/aibvol12_no3-hospitalist.pdf

Berenson, R. A., Ginsburg, P. B., \& May, J. H. (2007, January-February). Hospital-physician relations: Cooperation, competition, or separation? Health Affairs, 26(1), w31-w43. PubMed http://dx.doi. $\operatorname{org} / 10.1377 /$ hlthaff.26.1.w31

Centers for Medicare \& Medicaid Services (2013). ICD-9-CM: Retrieved from http://www.cms.gov/Medicare/Coding/ ICD9ProviderDiagnosticCodes/index.html

Health Resources and Services Administration, Bureau of Health Professions, National Center for Health Workforce Analysis (2013 November). Projecting the supply and demand for primary care practitioners through 2020. Retrieved from http://bhpr.hrsa.gov/healthworkforce/ supplydemand/usworkforce/primarycare/ projectingprimarycare.pdf

Kuo, Y. F., Sharma, G., Freeman, J. L., \& Goodwin, J. S. (2009, April 19). Growth in the Care of Older Patients by Hospitalists in the United States. The New England Journal of Medicine, 360(11),
1102-1112. PubMed http://dx.doi.org/10.1056/ NEJMsa0802381

Meltzer, D., Manning, W. G., Morrison, J., Shah, M. N., Jin, L., Guth, T., \& Levinson, W. (2002, December 3). Effects of physician experience on costs and outcomes on an academic general medicine service: Results of a trial of hospitalists. Annals of Internal Medicine, 137(11), 866-874. PubMed http://dx.doi.org/10.7326/0003-4819137-11-200212030-00007

Pham, H. H., Devers, K. J., Kuo, S., \& Berenson, R. (2005). Health care market trends and the evolution of hospitalist use and roles. Journal of General Internal Medicine, 20(2), 101-107. PubMed http://dx.doi.org/10.1111/j.15251497.2005.40184.x

Research Data Assistance Center (2013). Claim Attending Physician NPI Number. Retrieved fromhttp://www.resdac.org/cms-data/variables/ Claim-Attending-Physician-NPI-Number

SocietyofHospital Medicine(2011)Media Kit.2011. Retrieved from http://www.hospitalmedicine. org/content/navigationmenu/media/mediakit/ shm_mediakit1213.pdf

Wachter, R. M., \& Goldman, L. (1996, August 15). The emerging role of "hospitalists" in the American health care system. The New England Journal of Medicine, 335(7), 514517. PubMed http://dx.doi.org/10.1056/ NEJM199608153350713

Welch, W. P., Cuellar, A. E., Stearns, S. C., \& Bindman, A. B. (2013, September). Proportion of Physicians in Large Group Practices Continued to Grow in 2009-11. Health Affairs, 32(9), 1659-1666. PubMed http://dx.doi.org/10.1377/ hlthaff.2012.1256 